\title{
Complications associated with red blood cell (RBC) transfusions in the very low birth weight (VLBW) infant
}

\section{Abstract}

Background: Both prematurity and transfusions predispose to compromised outcome in very low birth weight infants.

Methods: We retrospectively examined correlations of outcome with frequency of RBC transfusions and age of blood transfused to VLBW infants admitted to a level III neonatal intensive care unit between January $1^{\text {st }}$, and December $31^{\text {st }}, 2008$. Short and long term outcome data of the transfused were compared with the non-transfused. Correlation coefficient and multivariate analysis were applied for correlations within the transfused group. Significance was assessed at $\mathrm{p}<0.05$.

Results: Of 189 VLBW infants identified; $106(56 \%)$ received a mean $7.9 \pm 7.8$ (median 5) transfusions/infant, with a mean volume of $147 \pm 183$ (median 94) $\mathrm{ml} /$ infant. Transfused VLBW infants compared to those non-transfused had lower gestational age (GA), higher number of ventilator and length of stay (LOS) days. They also had higher incidence of intraventricular haemorrhage (IVH) $>$ grade $2(14.9 \%$ vs $3.2 \%)$, retinopathy of prematurity (ROP) $>$ stage $2(15.2 \%$ vs $0 \%)$, Sepsis $(30.8 \%$ vs $4.9 \%$, p.001), and mortality $(15.1 \%$ vs $3.6 \%$, p.009). There were 25 cases of necrotizing enterocolitis (NEC), 19 of them (76\%) were preceded by transfusions within 72hours. Leukocytosis (p.o42) with relative granulocytosis (p.012) was seen at 24hours, and lymphopenia (p.035) at 12hours post transfusion. Multivariate regression analysis adjusting for $\mathrm{GA}$, showed that frequent transfusions were associated with sepsis, ROP $>$ stage II and IVH> grade II (OR 1.136, 1.056 and 1.036 respectively, p.001). RBCs older than 14days were associated with longer LOS (p.001) but no significant adverse associations seen on the multivariate analysis.

Conclusion: Transfusions are frequent in the VLBW infants and were associated with sepsis and post-transfusion NEC. Higher frequency of transfusions was associated with sepsis, severe ROP and IVH, while Older RBCs had no ill associations when adjusting for GA. Posttransfusion changes in white cell count and its subgroups may suggest inflammation and/or immunomodulation that warrant further investigation.

Keywords: neonatal anemia, transfusions, necrotizing enterocolitis, retinopathy of prematurity, premature, age of blood, neonatal mortality, neonatal sepsis
Volume 2 Issue 3 - 2015

\author{
Nabil Hassan, Jelanie Bush, Alice Foster, \\ Angela Andrews, Diann Reischman, David \\ Alter, Steven L Gelfand \\ 'Division of Pediatric Critical Care, Helen DeVos Children's \\ Hospital, USA \\ 2Department of Pediatrics, Bronson Methodist Hospital, USA \\ 'Divisionof Gastroenterology, British Columbia Children's \\ Hospital, Canada \\ ${ }^{4}$ Department of Internal Medicine - Pediatrics, Detroit Medical \\ Center/Wayne State University, USA \\ ${ }^{5}$ Department of Biostatistics, Grand Valley State University, USA \\ ${ }^{6}$ Department of Pathology, Spectrum Health, USA \\ 'Division of Neonatology, Mercy Health Saint Mary's Hospital, \\ USA
}

Correspondence: Nabil E Hassan, Division of Pediatric Critical Care, Helen DeVos Children $\square$ s Hospital, 100 Michigan Street NE MC\#I I7, Grand Rapids MI 49503, USA, Tel 6I6-267-0II5, Fax 616-267-0090, Email nabil.hassan@helendevoschilderns.org

Received: April 14, 20I5 | Published: June 26, 2015
Abbreviations: VLBW, very low birth weight; RBC, red blood cell; NICU, neonatal intensive care unit; NEC, necrotizing enterocolitis; VON, vermont-oxford network; ROP, retinopathy of prematurity; IVH, intraventricular hemorrhage; IRB, institutional review board

\section{Introduction}

Very low birth weight (VLBW) infants are prone to variety of complications during their often prolonged neonatal intensive care unit (NICU) stay. During their course they are exposed to multiple interventions that could potentially increase their morbidity and mortality risks as well. Red Blood Cell (RBC) transfusions are one of the most frequent interventions needed in caring for these infants. Nearly $80 \%$ of the VLBW population requires transfusions and frequently multiple. ${ }^{1,2}$

The premature baby is especially prone to anemia due to depressed erythropoietin production and repeated phlebotomy losses. This could be further complicated by several other factors including inadequate oxygenation from lung disease, patent ductus arteriosus, and/or concurrent acute illness. ${ }^{3,4}$ The potential for over utilization of transfusions in VLBW babies has been recognized for decades and conservation strategies have been implemented to reduce the frequency of transfusions with relative success. ${ }^{5-7}$ Surveys on neonatal transfusion practices still continue to show wide variability between various neonatal units over the past two decades. ${ }^{8,9}$ Even NICUs within the same system and operating under similar guidelines still show such variation in transfusion practices. ${ }^{10}$ One possible explanation for the observed variation is the uneven implementation of conservation strategies, and the fact that clear evidence-based indications for transfusions are still poorly-defined. Earlier transfusion protocols recommended higher transfusion thresholds in the face of increased oxygen demand and younger age. ${ }^{11}$ Meanwhile more guidelines recommend lower hemoglobin triggers for transfusions, while incorporating other indicators such as those of hemodynamic instability and hypoproliferative bone marrow state as reflected by low reticulocyte count in the presence of severe anemia. ${ }^{12-14}$

Transfusions have well-recognized infectious and allergic complications. Additionally, concerns over potential immune mediated,$^{15}$ and iron related ill effects have become increasingly recognized. ${ }^{16-18}$ Associations with higher mortality, higher frequency of infections, and longer mechanical ventilation needs in critically ill 
children have been reported, ${ }^{19}$ while In the case of premature babies associations with higher grade retinopathy of prematurity (ROP), acute lung injury, ${ }^{20}$ and necrotizing enterocolitis (NEC) have been reported. ${ }^{21,22}$ The storage age of blood has been shown to confer added risk for complications as suggested by several studies in the pediatric population; ${ }^{22-25}$ however a prospective randomized clinical study did not find this to be the case in the VLBW population. ${ }^{26}$

This study aimed to compare immediate and long term outcomes between transfused vs. non-transfused VLBW babies, and attempt to correlate those outcomes in the transfused with the frequency of transfusions and storage age of the transfused RBCs.

\section{Materials and methods}

\section{Study setting and population}

All babies $<1500 \mathrm{gm}$ admitted to a level III NICU at a referral children's hospital between January 1, 2008 and December 31, 2008. VLBW babies were identified in the data retrieved from the VermontOxford network (VON) database, as well as demographics and long term outcome data. Inclusion criteria were all infants less than $1500 \mathrm{gm}$ birth weight that survived beyond the first 24hours of life, and were either born on site or transferred from other lower acuity units for further care. Also included were infants transferred briefly to another institution for retinal surgery and were transported back (those were stable older infants). Excluded were those that deceased within 24 hours of birth, those $\geq 1500$ gram at birth, and those required extracorporeal membrane oxygenation( all were $>1500$ grams birth weight).

The hospital's blood bank database was used to identify those transfused, extract the number, volume, age of RBC, and time of the transfusions. The patient's electronic medical records were individually reviewed to extract short term events following the transfusions. Short term outcome data included fever, blood pressure, blood gases, acute lung injury (sustained increase in $\mathrm{FiO} 2$ needs, and if with $\mathrm{P} / \mathrm{F}$ ratio was $<300$ ), and rising blood lactate within 24 hours of transfusion. Sepsis and/or meningitis (defined by a positive blood culture or spinal fluid cultures) were counted as sepsis given the frequent association. White cell counts all within before and within 48hours post transfusions were collected. Confirmed NEC cases were counted; those preceded by RBC transfusion within 72 hours were identified.

Long term outcome data included length of NICU stay (LOS), mortality, mechanical ventilation days if longer than 24hours, retinopathy of prematurity (ROP) $>$ stage II, and intraventricular hemorrhage (IVH) greater than grade II. Definitions were as defined by the VON database entry criteria (Appendix 1). Excluded were infants that died within 24hours of admission. Also ventilator support less than 24 hours, $\mathrm{ROP} \leq$ stage 2 and $\mathrm{IVH} \leq$ grade II findings were excluded.

\section{Statistical analysis}

Quantitative variables were compared using the unpaired t-test for unequal variance, while nominal data were compared using the chi-square or Fisher's exact test. For categorical outcome data odds ratio was also calculated. On a continuous scale Pearson's correlation (R) with t-test ( $p$ value) for large samples and Spearman's rho test with $p$ value for smaller sample size were used to test age of blood correlation with parametric outcome endpoints. Logistic regression was used to test for associations between multiple variables and the dichotomous outcome variables ROP, IVH, and sepsis. The explanatory variables were number of transfusions, blood storage age, and volume transfused. Linear regression models were used for the continuous outcome variables LOS and ventilator days. Significance was assessed at $\mathrm{p}<0.05$.

\section{Waiver of consent}

Institutional Review Board (IRB) approval was obtained to conduct the study. Given its retrospective observational nature the need to obtain prior consents was waived.

\section{Results}

Nine hundred and fifty two neonates were admitted to the NICU from January 1 -December 31, 2008. After exclusion of 19 babies due to early death; 189 VLBW babies were identified.106 of $189(56 \%)$ of the VLBW babies were transfused with a total of 834 transfusions (mean 7.87 \pm 7.85 , median 5). The total volumes of PRBCs transfused were available in 783 of 834 transfusions (93\%), with a mean volume of $147 \pm 183$ (median 94)ml/ baby. Transfused VLBW babies compared to those nontransfused had lower gestational age, smaller birth weight, longer ventilator days, and longer LOS. These patient also had higher comorbidities such as IVH $>$ grade 2, ROP $>$ stage 2. Incidence of those who had at least one confirmed sepsis episode and mortality was significantly higher as well (Table 1).

\section{Associated short term effects in the transfused cohort}

Following transfusions there were clinically minor but statistically significant increase in mean BP (pre $44 \pm 12$, 6hours post $46 \pm 13 \mathrm{p} .001$, 12 hours post, $45 \pm 12$ p.001). No change was noted in FiO2, PO2, P/F ratio, temperature, or serum lactate. There was a significant increase in absolute WBC count the first 48 hours post transfusion, a relative increase in PMNs and decrease in lymphocytes percentages (Figure 1). No significant changes were seen in absolute or relative bands, eosinophils, or monocytes counts.

\section{Associated long term effects in transfused VLBW infants}

The number and volume of transfusions were available in 106 and 87 infants respectively. The unadjusted odds of higher volume and number of transfusions were significantly higher with younger GA and birth weight. The unadjusted odds were also significantly higher with higher grade IVH, higher stage ROP, as well as ventilator and LOS days.

\section{Associated outcomes and storage age of transfused RBCs}

Age of blood in days was available for 528 of 832 transfusions. There were 97 babies with at least one and 83 with all blood age available. Of the 528 transfusions available for analysis, $36(6.9 \%)$ were <7days, $158(29.9 \%)$ were 7-13days, $203(38.4 \%)$ were 14 20days, $107(20.3 \%)$ were21-27days, and $24(4.5 \%)$ were $\geq 28$ days. Overall mean age of blood was $16.1 \pm 6.3$ days (median16days).

\section{On a continuous scale}

There was a correlation between older RBCs and lower white blood cell (WBC) count at 24hours (R-.154, P.026), lower polymorphonuclear neutrophils (PMNS) (R-.534, P.049), and higher monocytes count(rho.58, P.043) at 48 hours post transfusion compared to baseline. On a continuous scale there was also a statistically significant correlation of older blood with lower mortality (spearman's rho.479, p.001). However patients who had complete or partial lack of age of blood transfused were excluded since the maximum age 
of transfused RBCs could not be determined. The deceased group had a higher number of transfusions per patient (dead $n=16,9.6 \pm 8.6$ transfusions/infant Vs. alive $\mathrm{n}=90,7.6 \pm 7.7$ transfusions/infant) with higher likelihood of receiving older blood, however half of them were excluded due to lack of maximum age of blood ( 8 of $16,50 \%)$, compared to the surviving group (15 of $90,16.7 \%$ ) (Table 2 ).

\section{On an interval basis}

Several outcome parameters were compared for those who received RBCs younger or older than 14, 21 and 28days. Of the 97 patients who had RBCs age data available, 14 had incomplete age of blood for all units transfused, and they were excluded or partially included based on the maximum age of blood given. Since all patients receiving blood less than 14 days old had 4 transfusions or less, in order to minimize the effect of the number of transfusions as a confounder we only compared patients who had a maximum of four transfusions.

There were several clinically insignificant short term outcome variables that reached statistical significance. A small decrease in WBCs at 24hours post -transfusion from pre- transfusion value for blood older than 14 days compared to an increase in those received blood less than 14days old $(-.21 \mathrm{k} \pm 5.67 \mathrm{Vs}+1.28 \mathrm{k} \pm 8.9$, p.049). A slight decrease in $\mathrm{FiO} 2$ requirement occurred with $\mathrm{RBCs}$ older than

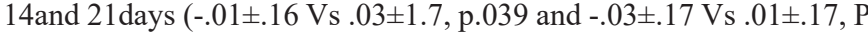
.023 respectively) 6hours post transfusion, and with blood older than 14,21 and 28 days $(-.01 \pm .17 .03 \pm .18$, p. $.019,-.02 \pm .16$ Vs. $01 \pm .18$, p. .031 and $-.04 \pm .09$ Vs. $01 \pm .18$, p.028 respectively) 12 hours post transfusion compared to younger blood. Also a clinically insignificant increase in PO2 was observed at 12 hours post transfusion for blood older than 14days compared to younger blood ( $3.54 \pm 15$ Vs $1.49 \pm 11$, p.047).

There was a statistically significant longer length of stay in survivors who received RBC older than 14 and 21 days ( Figure 2). Increased number of ventilator days with older RBCs was also seen, but lost significance when only patients receiving $\leq 4$ transfusions were compared (Table 3 ).

Table I Comparison of Transfused versus Non-Transfused Very Low Birth Weight babies

\begin{tabular}{|c|c|c|c|}
\hline Variables & Not Transfused $(n=83)$ & Transfused $(n=106)$ & $P$ value (Test) \\
\hline Birth Weight (gm) & $1264 \pm 183$ & $919 \pm 275$ & $0.001 *$ \\
\hline Female Gender n (\%) & 44 (53\%) & $5 \mathrm{I}(48 \%)$ & $0.504 * * *$ \\
\hline Gestational Age (weeks) & $29.8 \pm 2.1$ & $26.6 \pm 2.5$ & $0.001 *$ \\
\hline \multirow[t]{2}{*}{ Ventilator Days } & $19.8 \pm 39.3$ & $47.2 \pm 64.6$ & $0.018^{* *}$ \\
\hline & Median: 3 & Median: 23 & \\
\hline \multirow[t]{2}{*}{ Length of Stay } & $42.1 \pm 32.9$ & $104.3 \pm 79.2$ & $0.00 I^{*}$ \\
\hline & Median: 37 & Median: 83 & \\
\hline Mortality (\%) & $3(3.6 \%)$ & $16(15.1 \%)$ & $0.009 * * *$ \\
\hline $\mathrm{IVH}>$ Grade 2 & $2 / 62(3.2 \%)$ & I5/I0I (I4.9\%) & $0.018 * * *$ \\
\hline ROP> Stage II & $0 / 37(0 \%)$ & $14 / 92(15.2 \%)$ & $0.010(\mathrm{~F})$ \\
\hline Sepsis, Infant's n (\%) & $4 / 8 \mathrm{I}(4.9 \%)$ & $32 / 104$ (30.8\%) & $0.00 I^{* * *}$ \\
\hline
\end{tabular}

*:T-test; **: Mann Whitney test; ***: Chi-square test; F: Fisher's exact test; IVH: Intraventricular Hemorrhage; ROP: Retinopathy of Prematurity

Table 2 Association of Higher Number of Transfusions and Larger Volume Transfused with Outcome Variables

\begin{tabular}{|c|c|c|}
\hline Variables & Higher Number of Transfusions $(n=106)$ & Larger Volume Transfused $(n=87)$ \\
\hline Lower Birth Weight (gm)* & rho $-0.577,(p .00 I)$ & rho $-0.474,(p .00 I)$ \\
\hline Younger GA (weeks)* & rho $-0.56 I,(p .00 I)$ & rho $-0.502,(p .00 I)$ \\
\hline IVH> Grade2 (OR, p-value)** & OR I.065 (I.002 - I.I32, p.042) & OR=I.003 (p.086) \\
\hline ROP>Stage 2 (OR, p-value)** & OR I.3I4 (CII.I54-I.496, p.00I) & ORI.0I8 (CII.007-I.028, p.00I) \\
\hline Ventilator Days* & rho 0.782 (p.00I) & rho 0.760 (p.00I) \\
\hline Sepsis within 48 hours (OR, p-value) $)^{* *}$ & OR I.I36 (I.063-I.2 I4,p.00I) & ORI.003 (p.I29) \\
\hline Mortality Rate (OR, p-value)** & OR 0.97 (p.35I) & OR I.0 (p.88I) \\
\hline LOS (days)* & rho 0.669 (p.00I) & rho $0.656(p .656)$ \\
\hline
\end{tabular}

*:Spearman's rho for associations of continuous variables; **: OR, odds ratio (p-value) for categorical variables; ROP: Retinopathy of Prematurity; GA: Gestational Age; IVH: Intraventricular Hemorrhage

Table 3 Outcome comparisons of the transfused Very Low Birth Weight Infants based on an Intermittent Scale for the Age of RBC transfused

\begin{tabular}{|c|c|c|c|}
\hline Age of RBCs & $<\mid 4$ days $(n=15)$ Vs. $>14$ days $(n=34)$ & $<2 I$ days $(n=28)$ Vs. $\geq 2 I$ days $(n=2 I)$ & $\begin{array}{l}<28 \text { days } z(n=43) \text { Vs. } \\
\geq 28 \text { days }(n=6)\end{array}$ \\
\hline Transfusions $\mathrm{n} \pm \mathrm{SD}$ & $\mathrm{I} .7 \pm 0.9 \mathrm{Vs} .2 .3 \pm \mathrm{I} .2$ & $1.9 \pm 1.0$ Vs. $2.5 \pm 1.2$ & $2.1 \pm 1.8 \mathrm{Vs} .2 .2 .14 \pm 1.2$ \\
\hline $\mathrm{p}$ value* & $\mathrm{p}<0.069$ & $\mathrm{p}<0.05$ & $p<0.917$ \\
\hline Birth Weight (grams \pm SD) & $1025 \pm 332$ Vs. $1053 \pm 228$ & $1094 \pm 292$ Vs. $979 \pm 200$ & $1054 \pm 256$ Vs. $975 \pm 308$ \\
\hline $\mathrm{P}$ value $*$ & $\mathrm{p}<0.845$ & $p<0.042$ & $\mathrm{p}<0.502$ \\
\hline Gestational Age (weeks \pm SD) & $27.4 \pm 2.72$ Vs. $2.5 \pm 2.1$ & $27.9 \pm 2.37$ Vs. $27.0 \pm 1.7$ & $27.5 \pm 2.2$ Vs. $28 \pm I . I$ \\
\hline $\mathrm{P}$ value $*$ & $\mathrm{p}<0.456$ & $p<0.054$ & $\mathrm{p}<0.755$ \\
\hline Sex, Females (\%) & 6(40.0\%) Vs. 19(55.9\%) & II (39.3\%) Vs. I4(66.7\%) & $20(46 \%)$ Vs. $5(83 \%)$ \\
\hline $\mathrm{P}$ value $* * *$ & $\mathrm{p}<0.305$ & $p<0.058$ & $\mathrm{p}<0.189 *$ \\
\hline Ventilator Days \pm SD & $3.2 \pm I .3(n=5)$ Vs. $I 3.0 \pm 17 . I(n=19)$ & $6.2 \pm 5.7 \mathrm{Vs} .16 .64 \pm 21.5$ & $1 \mathrm{I} .7 \pm \mid 6.2 \mathrm{Vs} .2$ \\
\hline $\mathrm{P}$ value* & $\mathrm{p}<0.053$ & $p<0.167$ & $\mathrm{p}<0.464$ \\
\hline Mortality n (\%) & $5(33.3 \%)$ Vs. I (2.9\%) & $6(2 \mathrm{l} .4 \%) \mathrm{Vs} .0(0 \%)$ & $6(14.0 \%)$ Vs. $0(0 \%)$ \\
\hline
\end{tabular}


Table Continued...

\begin{tabular}{|c|c|c|c|}
\hline Age of RBCs & $<\mid 4$ days $(n=\mid 5)$ Vs. $>\mid 4$ days $(n=34)$ & $<2 I$ days $(n=28)$ Vs. $\geq 2 I$ days $(n=2 I)$ & $\begin{array}{l}<28 \text { days } z(n=43) \text { Vs. } \\
\geq 28 \text { days }(n=6)\end{array}$ \\
\hline$P$ value $* *$ & $p<0.008$ & $\mathrm{p}<0.031$ & $\mathrm{p}<1.000$ \\
\hline LOS for Survivors Days \pm SD & $56.4 \pm 16.8$ Vs. $71.5 \pm 19.9$ & $59.2 \pm|4$.$| Vs.77.2 \pm 21.5$ & $66.9 \pm 20.3$ Vs.74.6 $\pm 18.6(n=6)$ \\
\hline P value* & $\mathrm{p}<0.00 \mathrm{I}$ & $\mathrm{p}<0.001$ & $\mathrm{p}<0.247$ \\
\hline IVH > Grade 2 n (\%) & $2(13.3 \%)$ Vs. I(2.9\%) & 2 (7.I\%) Vs. I(4.8\%) & $3 / 39(7 \%)$ Vs. $0 / 6(0 \%)$ \\
\hline $\mathrm{P}$ value ${ }^{* *}$ & $\mathrm{p}<0.143$ & $\mathrm{p}<1.000$ & $\mathrm{p}<1.000$ \\
\hline Sepsis n (\%) & $\mathrm{I}(6.7 \%) \mathrm{Vs.} 5(\mid 4.7 \%)$ & $2(7.1 \%)$ Vs. 4(19.5\%) & $6(14 \%)$ Vs. $0(0 \%)$ \\
\hline $\mathrm{P}$ value $\mathrm{e}^{* *}$ & $\mathrm{p}<1.000$ & $\mathrm{p}<0.386$ & $\mathrm{p}<1.000$ \\
\hline
\end{tabular}

*: Mann Whitney; **: Fisher; ***: Chai-square; n: number of patient

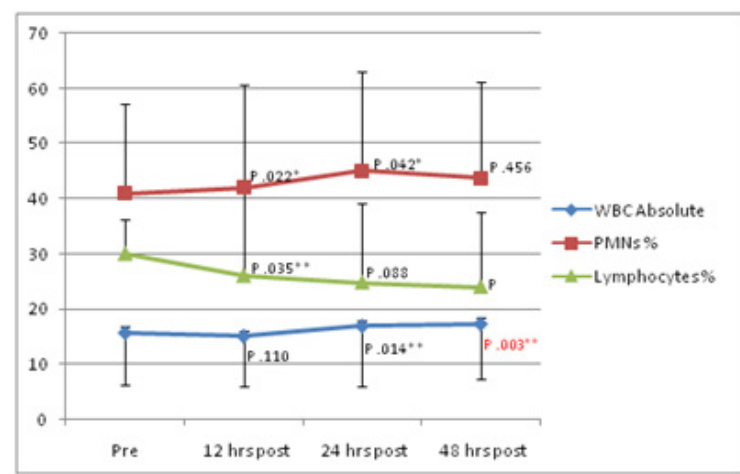

Figure I Changes in white cell count following transfusions in Very Low Birth Weight babies.

*: T-test; **: Chi-square; WBC count is $x 102$; PMN: Polymorphonuclear Neutrophils;WBC:White Blood Cells

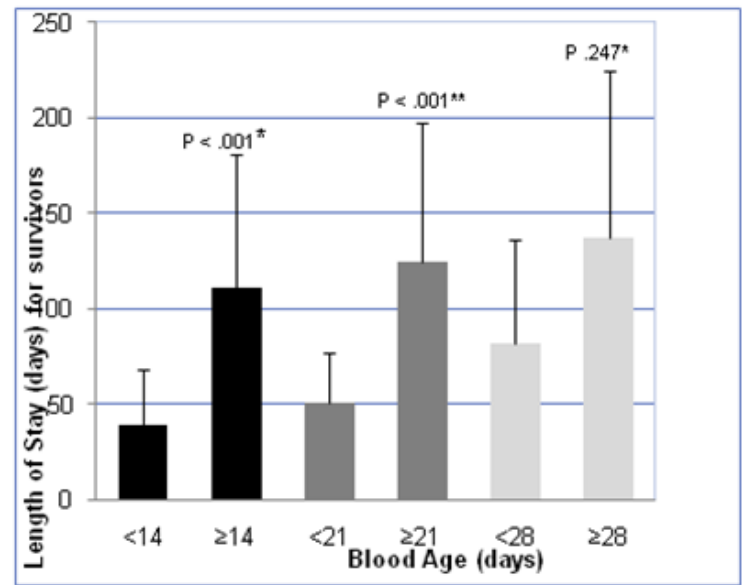

Figure 2 Hospital length of stay and age of blood in those received $\leq 4$ transfusions.

Meanwhile, older blood had an association with lower mortality ( $2.9 \%$ Vs $3.3 \%$ p.008 at 14 days, $0 \%$ Vs $21.4 \%$ p. 031 at 21 days, and $0 \% \mathrm{Vs} 14 \%$ p 1.00 at 28days). That difference was present even when those received more than 4 transfusions were included. Similar to the continuous correlation testing, lack of maximum age of blood in many nonsurvivors biased the result. Age of blood had no association with any adverse short term physiologic or laboratory parameters, incidence of sepsis, ROP $>$ grade 2, or IVH $>$ grade 2 on either the continuous or interval scales.

\section{Incidence of NEC, transfusions, and age of blood}

Twenty five cases of Confirmed NEC occurred in the transfused VLBW and non in the nontransfused group. 19 of those (76\%) were transfused within the 72hours prior to making the diagnosis, (p0.009).
Age of blood for this group was $16.1 \pm 6.3$ days (range 6-21); with 7 transfusions older than, and 7 younger than 14 days. In the remaining 5 cases, the age of the blood transfused was not available for our analysis.

\section{Multivariate regression analysis}

Incorporating maximum age of blood, number and volume of transfusions, and gestational age (GA) revealed that higher number of transfusions was significantly associated with IVH $>$ grade II OR 1.056 (CI 1.002-1.132, p.042), ROP $>$ stage II OR 1.016 (CI 1.0701.369, p.002), and higher incidence of sepsis OR 1.136(CI 1.0631.214, p.001) (Figure 3). Higher volume transfused was significantly associated with only ROP > stage II OR 1.016 (CI 1.002-1.030, p.022) (Figure 4). Age of blood did not correlate with IVH, ROP or Sepsis.

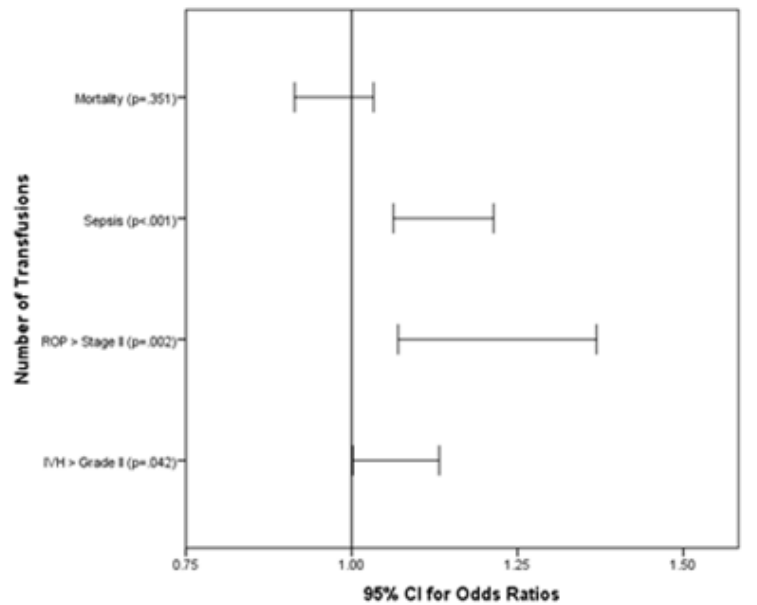

Figure 3 Correlation of number of transfusions and outcome in VLBW infants.

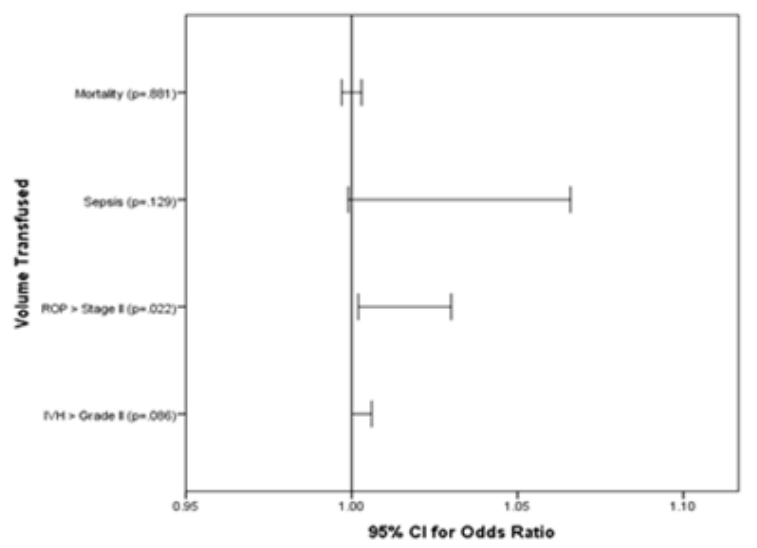

Figure 4 Correlation of volume of RBC transfused and outcome in theVLBW infants. 


\section{Discussion}

Red blood cell transfusions continue to be a frequent occurrence while caring for the VLBW infants. Fifty six percent of our cohort received a median of 5 transfusions: $84 \%$ of those occurring in the ELBW subgroup. Transfusion rates have continued to decrease over the last decades. Some factors contributing to the falling rates are the implementation of conservative transfusion guidelines, ${ }^{7}$ utilization of erythropoiesis stimulating agents (ESAs), ${ }^{14}$ and practical measures such as the substitution of umbilical cord blood for the barrage of tests that newborns frequently need. ${ }^{27}$ Premature infants are inherently prone to adverse outcomes such as CLD, sepsis, NEC and IVH, ${ }^{28}$ hence it is difficult to elucidate if transfusion is an independent risk that is contributing to a specific outcome parameter, or it is rather a marker of severity of illness.

Meanwhile there is an accumulating evidence of associated complications in the transfused premature babies. Valieva et al., reported a higher incidence of severe ROP in the transfused VLBW, while Fortes Filhodemonstrated its association with higher volume of RBC transfused..$^{29}$ A retrospective case controlled study also showed increased likelihood of Intraventricular hemorrhages in transfused patients..$^{30}$ Similarly, the incidence of CLD was suggested to correlate with RBC transfusions in earlier reports. ${ }^{31,32}$ While more recently, Chen et al., ${ }^{33}$ demonstrated that VLBW babies transfused more than $30 \mathrm{ml} / \mathrm{kg}$ had a significant increase of adjusted odds for developing CLD. ${ }^{33}$ This later finding however was not evident in our cohort.

Dos Santos et al., ${ }^{34}$ presented the strongest evidence for the association between increased mortality and RBC transfusions. In a prospective comparison that adjusted for several confounders of acuity and included 8 neonatal centers, VLBW infants who received one transfusion had a relative risk of death of 1.49 , and those received 2 transfusions had a relative risk of 1.89 . In their population transfusion rate was similar to ours at $53 \%$, and infants received an average of 3.4 transfusions per baby. ${ }^{34}$

Transfused infants in our study compared to the non-transfused were younger, and smaller in weight, which certainly places them at risk for the observed higher incidence of severe IVH and ROP, sepsis and higher ventilator days. Similar findings were also noticed in the results of the univariate regression analysis looking at different outcome parameters in relation to the number of the transfusions and volume of blood transfused.

The relationship between older RBC's and worse outcomes is consistent with studies in PICU patients in previous reports. Gauvin et al. ${ }^{24}$ prospectively demonstrated that transfusions with RBC older than 14days were associated with Multi-organ dysfunction (MOD) and higher mortality at 21 days. ${ }^{24}$ Karam et al., ${ }^{25}$ similarly showed prospectively the correlation of MOD with RBC older than 14days in the PICU patients. ${ }^{25}$ In a recent retrospective single center review, we have reported higher mortality intrauma patients that were transfused older blood. ${ }^{23} \mathrm{~A}$ similar finding of increased mortality was reported in adult trauma patients, ${ }^{35}$ but was not seen in burn patients. ${ }^{36}$ Fergusson et al., ${ }^{26}$ in a multicenter prospective study of VLBW babies showed that infants randomized to receive RBCs stored less than 7 days compared to standard issue had no difference in outcomes. ${ }^{26}$ In that report the age of blood was 5.1 Vs 14.6days in the two groups respectively. The authors acknowledged that a storage age of 14 days may not be sufficient to detect differences in outcome.

More recently Cholette et al., ${ }^{37}$ demonstrated in a pediatric cardiac surgery population, a quarter of which were neonates, that blood 25-38days old compared to 7-15days old was associated with post- operative infections even when the number of transfusion was limited to two. We stratified storage age into groups to better examine the effect of blood $>14$ days. In our cohort the average age of RBCs was 16 days, with only $20 \%$ of the infants given blood 21-28days old, and less than 5\% given blood older than 28days. Our blood bank guidelines limit the age of RBCs dispensed for VLBW babies to 28days, and to 35 days in older and larger infants. Such variation in the distribution of storage age does however dilute our ability to examine the effect of older blood. As such, the number of patients in the older blood groups is much smaller, and the higher the number of transfusions may be encountered in older babies that were more likely to receive older RBC. On an interval basis RBCs older than 14 and 21 days was associated with longer LOS even after excluding all mortalities that may shorten the LOS, and limiting the analysis to only those received 4 units of blood, since the maximum number of transfusions in the group that received blood younger than 14days, The latter adjustment corrects for the higher probability of receiving older blood with higher number of transfusions.

Of interest lower mortality was seen with older blood in the univariate analysis, however that observation is far from credible as we had to exclude patients with any missing age of blood. Those exclusions were disproportionately higher in the non survivors and resulted in much smaller non survivors in the older blood groups. On a continuous scale univariate analysis mortality again was associated with older blood. Multivariate analysis that included gestational age, volume and frequency of transfusions, as well as age of blood showed that there were no worse outcome parameters correlating with the age of blood. It showed that higher volume of RBCs transfused correlated with more advanced ROP, while a greater number of transfusions correlated with more advanced ROP, higher grade IVH and higher incidence of sepsis. Incidence of NEC as previously reported, ${ }^{22}$ correlated with a preceding transfusion in $76 \%$ or the cases, however, no evidence of correlation with age of blood was seen, particularly given the small sample size. Transfusion induced immunomodulation has been discussed in the literature and is supported by reports of increased morbidities in transfused hospitalized and surgical patients. ${ }^{38}$ Wang-Rodriguez et al., ${ }^{15}$ studied lymphocyte marker expression In the VLBW babies prior to and following RBC transfusions. He demonstrated an early stimulation followed by later suppression. ${ }^{15}$ In our study population, transfusion was associated with post-transfusion diagnoses of sepsis. Meanwhile transfusion induced inflammation was suggested by Wright et al. ${ }^{39}$ who reported a rise in white blood cell count following transfusions. ${ }^{39}$ We have similarly observed in our population a post transfusion increased white cell count primarily due to increased PMN while lymphocyte count tended to decline. Such pattern was reversed with older blood. This data may suggest an element of transfusion associated inflammation along with a possible immune alteration. It remain to be seen in future research if these findings are related in any way to our observed higher incidence of post transfusion sepsis, and the finding that $76 \%$ of the NEC cases were preceded by transfusions within 72 hours prior to diagnoses.

Our study is limited by several factors. The retrospective design limits the strength of the outcome parameters to a mere association that is prone to several recognized and unrecognized confounders. Transfused infants were younger and smaller than the not-transfuse; while the smaller infants received higher level of exposure to transfusions. Prematurity as mentioned earlier, in and by itself predispose to more severe lung, gut, and brain immaturity hence more severe lung disease, longer ventilator days, higher incidence of NEC and IVH. The more immature immune system also predispose to higher incidence of sepsis. Above all the sicker younger premature infants 
have more frequent phlebotomy losses in the face of smaller blood volume which results in the likelihood of more frequent transfusions. Simply put prematurity leads to more transfusions which are associated with complications known to be a product of prematurity. A second limitation was the lack of an acuity score to use to adjust for severity of illness as the study was conducted prior to adopting such practice in our NICU; however we have made several adjustments in the analysis including incorporating GA in the multivariate analysis. Lastly age of blood analysis is biased by the number of transfusions. The higher number of transfusions carries the higher probability of receiving older blood, hence we eliminated those received greater than 4 transfusions in the age of blood comparisons, as it was the maximum number received by the group that received blood younger than 14days. LOS analysis was also limited to survivors to minimize bias of mortality.

In summary, a significant number of VLBW infants still receive multiple transfusions and suffer from worse outcome. NEC was associated with RBC transfusions. On multivariate analysis adjusting for gestational age, higher number of RBC transfusions is associated with increased incidence of sepsis, severe ROP and IVH, whereas higher volume of PRBC's was only associated with >stage II ROP. Transfused RBC older than 14days when adjusted for the number of transfusions was associated with longer LOS; however, no ill effects were seen in the multivariate regression analysis. Changes in white cell count and lymphocytes may be a marker of inflammation and /or immune modulation which warrant further investigations.

\section{Acknowledgments}

None.

\section{Conflicts of interest}

Author declares there are no conflicts of interest.

\section{Funding}

None.

\section{References}

1. Valieva OA, Strandjord TP, Mayock DE, et al. Effects of Transfusions in extremely low birth weight infants. J Pediatr. 2009;155(3):331-337.

2. Bishara N, Ohls RK. Current controversies in the management of the anemia of prematurity. Semin Perinatol. 2008;33(1):29-34.

3. Juul S. Erythropoiesis and the approach to anemia in premature infants. J Matern Fetal Neonatal Med . 2012;25(Suppl 5):97-99.

4. Strauss RG. How I transfuse red blood cells and platelets to infants with anemia and thrombocytopenia of prematurity. Transfusion. 2008;48(2):209-217.

5. Widness JA. Pathophysiology, Diagnosis, and Prevention of neonatal anemia. NeoReviews. 2000; 1(4):e61-e68.

6. Bifano EM, Curran TR. Minimizing donor blood exposure in the neonatal intensive care unit. Current trends and future prospects. Clin Perinatol. 1995;22(3):657-669.

7. Baer VL, Henry E, Lambert DK, et al. Implementing a program to improve compliance with neonatal intensive care unit transfusion guidelines was accompanied by a reduction in transfusion rate: a prepost analysis within a multihospital health care system. Transfusion. 2011;51(2):264-269.

8. Guillén U, Cummings JJ, Bell EF, et al. International survey of transfusion practices for extremely premature infants. Semin Perinatol . 2012;36(4):244-247.
9. Strauss RG, Levy GJ, Sotelo-Avila C, et al. A national survey of transfusion practices: II. Blood component therapy. Pediatrics. 1993;91(3):530-536.

10. Henry E, Christensen RD, Sheffield MJ, et al. Why do four NICUs using identical RBC transfusion guidelines have different gestational ageadjusted RBC transfusion rates? J Perinatol . 2015;35(2):132-136.

11. Shannon KM, Keith JF, Mentzer WC, et al. Recombinant human erythropoietin stimulates erythropoiesis and reduces erythrocyte transfusions in very low birth weight preterm infants. Pediatrics. 1995;95(1):1-8.

12. Red blood cell transfusions in newborn infants: Revised guidelines. Paediatr Child Health. 2002; 7(8):553-566.

13. Bailey SM, Hendricks-Muñoz KD, Mally P. Splanchnic-cerebral oxygenation ratio as a marker of preterm infant blood transfusion needs. Transfusion. 2012;52(2):252-260.

14. Ohls RK, Christensen RD, Kamath-Rayne BD, et al. A randomized, masked, placebo-controlled study of darbepoetin alfa in preterm infants. Pediatrics . 2013;132(1):e119-e127.

15. Wang-Rodriguez J, Fry E, Fiebig E, et al. Immune response to blood transfusion in very-low-birth weight infants. Transfusion. 2000;40(1):25-34.

16. Hirano K, Morinobu T, Kim H, et al. Blood transfusion increases radical promoting non-transferrin bound iron in preterm infants. Arch Dis Child Fetal Neonatal Ed . 2001;84(3):F188-F193.

17. Collard KJ, Godeck S, Holley JE. Blood transfusion and pulmonary lipid peroxidation in ventilated premature babies. Pediatr Pulmonol. 2005;39(3):257-261.

18. Wardle SP, Drury J, Garr R, et al. Effect of blood transfusion on lipid peroxidation in preterm infants. Arch Dis child Fetal Neonatal Ed. 2002;86(1):F46-F48.

19. Bateman ST, Lacroix J, Boven K, et al. Anemia, blood loss, and blood transfusions in North American children in the intensive care unit. Am J Respir Crit Care Med . 2008;178(1):26-33.

20. Wu TJ, Teng RJ, Tsou Yau KI. Transfusion-related acute lung injury treated with surfactant in a neonate. Eur J Pediatr. 1996;155(7):589-591.

21. Mally P, Golombek SG, Mishra R, et al. Association of necrotizing enterocolitis with elective packed red blood cell transfusions in stable, growing, premature neonates. Am J Perinatol. 2006;23(8):451-458.

22. Mohamed A, Shah PS. Transfusion associated necrotizing enterocolitis: a meta-analysis of observational data. Pediatrics. 2012;129(3):529-540.

23. Hassan NE, DeCou JM, Reischman D, et al. Red Cell Transfusions in Children Requiring Intensive Care Admission after Traumatic Injury. Pediatr Crit Care Med. 2014;15(7):e306-e313.

24. Gauvin F, Spinella PC, Lacroix J, et al. Canadian Critical Care Trials Group and the Pediatric Acute Lung Injury and Sepsis Investigators (PALISI) Network: Association between length of storage of transfused red blood cells and multiple organ dysfunction syndrome in pediatric intensive care patients. Transfusion. 2010;50(9):1902-1913.

25. Karam O, Tucci M, Bateman ST, et al. Association between length of storage of red blood cell units and outcome of critically ill children: a prospective observational study. Crit Care. 2012;2010;14(2):R57.

26. Fergusson DA, Hébert P, Hogan DL, et al. Effect of Fresh Red Blood Cell Transfusions on Clinical Outcome in Premature, Very Low-Birth-Weight infants. The ARIPI Randomized Trial. JAMA .1308(14):1443-1451.

27. Baer VL, Lambert DK, Carroll PD, et al. Using umbilical cord blood for the initial blood tests of VLBW neonates results in higher hemoglobin and fewer transfusions. J Perinatol . 2013;33(5):363-365.

28. Jacob J, Kamitsuka M, Clark RH, et al. Etiologies of NICU Deaths. Pediatrics . 2015;135(1):e59-e65. 
29. Fortes Filho JB, Eckert GU, Valiatti FB, et al. The influence of gestationa age on the dynamic behavior of other risk factors associated with retinopathy of prematurity (ROP). Graefes Arch Clin Exp Ophthalmol. 2010;248(6):893-900.

30. Baer VL, Lambert DK, Henry E, et al. A Among very-low-birthweight neonates is red blood cell transfusion an independent risk factor for subsequently developing a severe intraventricular hemorrhage? Transfusion. 2011;51(6):1170-1178.

31. Cooke RW, Drury JA, Yoxall CW, et al. Blood transfusion and chronic lung disease in preterm infants. Eur J Pediatr. 1997;156(1):47-50.

32. Silvers KM, Gibson AT, Russell JM, et al. Antioxidant activity, packed cell transfusions, and outcome in premature infants. Arch Dis Child Fetal Neonatal Ed. 1998;78(3):F214-F219.

33. Chen HL, Tseng HI, Lu CC, et al. Effect of blood transfusions on the outcome of very low body weight preterm infants under two different transfusion criteria. Pediatr Neonatol. 2009;50(3):110-116.

34. dos Santos AM, Guinsburg R, de Almeida MF, et al. Brazilian Network on Neonatal Research. Red blood cell transfusions are independently associated with intra-hospital mortality in very low birth weight preterm infants. J Pediatr. 2011;159(3):371-376.
35. Spinella PC, Carroll CL, Staff I, et al. Duration of red blood cell storage is associated with increased incidence of deep vein thrombosis and in hospital mortality in patients with traumatic injuries. Crit Care. 2009;13(5):R151.

36. Cartotto R, Yeo C, Camacho F, et al. Does the storage age of transfused blood affect outcome in burn patients? J Burn Care Res. 2014;35(2):186-197.

37. Cholette JM, Pietropaoli AP, Henrichs KF, et al. Longer Storage Duration Is Associated With Increased Postoperative Infections in Pediatric Cardiac Surgery. Pediatr Crit Care Med. 2015;16(3):227-235.

38. Kneyber MC, Grotenhuis F, Berger RF, et al. Transfusion of leukocytedepleted RBCs is independently associated with increased morbidity after pediatric cardiac surgery. Pediatr Crit Care Med. 2013;14(3):298-305.

39. Wright IM, Skinner AM. Post-transfusion white cell count in the sick preterm neonate. J Paediatr Child Health. 2001;37(1):44-46. 